\title{
Pole Coordinates of the Asteroids 9 Metis, 22 Kalliope, and 44 Nysa
}

\author{
VINCENZO ZAPPALÀ \\ Astronomical Observatory of Torino, I0025 Pino Torinese, Italy
}

AND

\section{VAN HOUTEN-GROENEVELD}

Leiden Observatory, Huygens Laboratory, 2300 RA Leiden, The Netherlands

Received January 18, 1979; revised July 9, 1979

\begin{abstract}
By means of new photoelectric observations made in 1974 an attempt to determine the poles of asteroids 9 and 44 was made. Following a method based upon the magnitude-aspect and amplitude-aspect relations, the coordinates of the poles for 9 and 44 were found to be, respectively, $\lambda_{0}=191^{\circ} \pm 5^{\circ}, \beta_{0}=56^{\circ} \pm 6^{\circ}$ and $\lambda_{0}=100^{\circ} \pm 10^{\circ}, \beta_{0}=50^{\circ} \pm 10^{\circ}$. The previously published pole for asteroid $22, \lambda_{0}=215^{\circ} \pm 10^{\circ}, \beta_{0}=45^{\circ} \pm 15^{\circ}$, was confirmed. From its phase relation we determined the phase coefficient of 44 Nysa, a very high albedo object $\left(p_{v}=0.377\right)$. The very low phase coefficient obtained $\left(\beta_{v}=0.018 \mathrm{mag} / \mathrm{deg}\right)$ agrees very well with an inverse relation between geometrical albedo and phase coefficient. The results are summarized in a table.
\end{abstract}

\section{INTRODUCTION}

New photoelectric observations of asteroids 9,22 , and 44 were made by $W$. van Vliet and I. van Houten-Groeneveld at the Leiden Southern Station in Hartebeespoortdam, South Africa, from May 16 to June 23, 1974 and one single-night run of asteroid 22 was made on September 4, 1965, by C. J. van Houten and I. van HoutenGroeneveld. For informations on the instrumental facilities and methods of observation and reduction, we refer to Zappalà $e t$ al. (1979).

For both the asteroids 9 and 44 rotational properties over a large range in longitude had previously been obtained during six different oppositions from 1949 to 1974.

The new 1974 lightcurve of 22 Kalliope is a good check for the pole solution found by Scaltriti et al. (1978).

\section{THE METHOD FOR THE DETERMINATION OF THE POLE}

For the determination of the direction of the rotational axis we start with the method used by Sather (1976), which gives a pre- liminary range of possible poles. We then try to select a more accurate value taking into account the observed amplitudes. The assumption of a three-axial ellipsoid is always made, even if the observations on November 7, 1949, and October 29, 1964, display a broad secondary minimum; but in view of the aim of this paper to determine values of the pole coordinates only at first approximation, we do not consider it a serious problem.

Many of the observations available were performed at phase angles smaller than $8^{\circ}$ (i.e., in the range of the opposition effect). Scaltriti and Zappalà (1978), collecting all the magnitude values published to date for asteroids of different compositional types, confirmed that the opposition effect seems independent of the type, at least for large asteroids. They found that the opposition effect starts at a phase angle of 8.5 and can be represented by a parabola tangential to the straight line at 8.5 . The difference between the straight line extension at $0^{\circ}$ and the parabola at the same angle is about 0.28 mag. From this model it is possible to ex- 
TABLE I

Positions, Magnitudes, Colors, Amplitudes, and Comparison Stars

\begin{tabular}{|c|c|c|c|c|c|c|c|c|c|c|}
\hline \multirow{2}{*}{$\begin{array}{l}\text { As- } \\
\text { teroid }\end{array}$} & \multirow{2}{*}{$\begin{array}{l}\text { Mean Time of } \\
\text { observation } \\
\text { (UT) }\end{array}$} & \multirow{2}{*}{$\begin{array}{l}\text { R.A. } \\
(1950)\end{array}$} & \multirow{2}{*}{$\begin{array}{l}\text { Decl. } \\
(1950)\end{array}$} & \multirow{2}{*}{$\begin{array}{c}V_{0} \\
(\mathrm{mag})\end{array}$} & \multirow{2}{*}{$\begin{array}{c}\bar{V} \\
\text { (mag) }\end{array}$} & \multirow{2}{*}{$\begin{array}{l}B-V \\
\text { (mag) }\end{array}$} & \multirow{2}{*}{$\begin{array}{l}\text { Amp. } \\
\text { (mag) }\end{array}$} & \multirow{2}{*}{$\begin{array}{l}\text { Period } \\
\text { (Taylor) }\end{array}$} & \multicolumn{2}{|c|}{ Comparison star } \\
\hline & & & & & & & & & No. & $\underset{(\mathrm{mag})}{\mathrm{V}^{*}}$ \\
\hline 9 & 1974 Jun 23.985 & $19^{\mathrm{h}} 46^{\mathrm{m}} 0$ & $-26^{\circ} 36^{\prime}$ & 10.03 & 10.18 & 0.85 & 0.28 & $5^{\mathrm{h}} 3^{\mathrm{m}} 84$ & CoD $-26^{\circ} 14523$ & 8.83 \\
\hline 22 & 1965 Sep 4.910 & $20^{\mathrm{h}} 46^{\mathrm{m}} 2$ & $-36^{\circ} 49^{\prime}$ & 11.19 & 11.31 & 0.72 & 0.30 & $4^{\mathrm{h}} 8^{\mathrm{m}} 82$ & CoD- $36^{\circ} 14417$ & 8.54 \\
\hline 22 & 1974 Jun 12.868 & $15^{\mathrm{h}} 36^{\mathrm{m}} 4$ & $-18^{\circ} 36^{\prime}$ & 11.23 & 11.30 & 0.73 & 0.14 & - & BD- $18^{\circ} 4118$ & 5.36 \\
\hline 44 & 1974 May 16.951 & $16^{\mathrm{h}} 24^{\mathrm{m}} 5$ & $-15^{\circ} 58^{\prime}$ & 10.27 & 10.41 & 0.71 & 0.28 & $6^{\mathrm{h}} 25^{\mathrm{m}} 08$ & BD- $15^{\circ} 4324$ & 7.17 \\
\hline
\end{tabular}

TABLE II

Epochs of the Extrema Corrected for Lighttime

\begin{tabular}{lcccc}
\hline Asteroid & 9 & 22 & 22 & 44 \\
\cline { 2 - 4 } & 1974 Jun 23-24 & 1965 Sep 4 & 1974 Jun 12 & 1974 May $16-17$ \\
\hline JD(c) & 2442 222.0+ & $2439008.0+$ & $2442211.0+$ & $2442184.0+$ \\
$M$ I & 0.391 & 0.476 & 0.406 & 0.319 \\
II & $0.600:$ & & & $0.587:$ \\
$m$ I & 0.506 & 0.384 & 0.322 & 0.456 \\
$m$ II & 0.451 & 0.343 & 0.357 & 0.382 \\
& 0.549 & \pm 0.003 & 0.275 & 0.512 \\
\hline
\end{tabular}

TABLE III

Aspect Data and Magnitudes for 9 Metis

\begin{tabular}{|c|c|c|c|c|c|c|c|c|c|c|c|}
\hline $\begin{array}{c}\text { Date } \\
\left(\mathrm{O}^{\mathrm{h} U T}\right)\end{array}$ & $\begin{array}{c}\lambda(\mathrm{deg}) \\
(1950)\end{array}$ & $\begin{array}{c}\beta(\text { deg }) \\
(1950)\end{array}$ & $\begin{array}{c}\Delta \\
(\mathrm{AU})\end{array}$ & $\begin{array}{c}r \\
(\mathrm{AU})\end{array}$ & $\begin{array}{c}\alpha \\
\text { (deg) }\end{array}$ & $\begin{array}{c}V_{0}(1, \alpha) \\
(\mathrm{mag})\end{array}$ & $\begin{array}{l}\bar{V}(1, \alpha) \\
\text { (mag) }\end{array}$ & $\begin{array}{c}\text { Amp } \\
\text { (mag) }\end{array}$ & $\begin{array}{c}B-V \\
\text { (mag) }\end{array}$ & Period & Reference \\
\hline 1949 Nov 2 & 41.12 & -5.00 & 1.145 & 2.134 & 2.5 & 6.33 & 6.40 & 0.11 & - & $5^{\mathrm{h}} 3^{\mathrm{m}}$ & $\mathrm{a}$ \\
\hline 1954 Jan & 98.56 & +5.42 & 1.138 & 2.118 & 3.0 & 6.63 & 6.76 & 0.26 & 0.84 & $5^{\mathrm{h}} 4^{\mathrm{m}} 6$ & $\mathrm{~b}$ \\
\hline $1954 \mathrm{Jan}$ & 98.06 & +5.52 & 1.141 & 2.119 & 3.8 & 6.69 & - & 0.26 & 0.85 & $5^{\text {h }} 4 m 6$ & $\mathrm{~b}$ \\
\hline 1954 Jan 8 & 97.31 & +5.64 & 1.148 & 2.121 & 5.2 & 6.77 & - & - & 0.85 & $5^{\mathrm{n}} 4^{\mathrm{m}} \cdot 6$ & b \\
\hline $1954 \operatorname{Jan} 16$ & 95.51 & +5.90 & 1.177 & 2.126 & 9.4 & 6.96 & 7.09 & 0.25 & 0.85 & $5^{\text {h }} 4 \mathrm{~m} 6$ & $\mathrm{~b}$ \\
\hline 1958 Feb 15 & 152.95 & +9.65 & 1.309 & 2.284 & 5.2 & 6.52 & 6.57 & 0.09 & 0.84 & - & $\mathrm{c}$ \\
\hline $1962 \operatorname{Mar} 26$ & 194.84 & +7.85 & 1.504 & 2.487 & 5.1 & - & - & 0.06 & - & $5^{\text {h }} 3 m 84$ & $\mathrm{~d}$ \\
\hline $1962 \operatorname{Mar} 30$ & 193.84 & +7.79 & 1.501 & 2.492 & 3.7 & - & - & 0.06 & - & $5^{\text {h. }} 3 \mathrm{~m} .84$ & $\mathrm{~d}$ \\
\hline 1964 Nov 19 & 94.37 & +1.46 & 1.223 & 2.092 & 16.8 & 一 & - & $0.31:$ & - & $5^{\mathrm{h}} 6^{\mathrm{m}}$ & $\mathrm{e}$ \\
\hline 1974 Jun 24 & 293.63 & -5.30 & 1.656 & 2.624 & 8.5 & 6.84 & 6.99 & 0.28 & 0.85 & $5^{\text {h }} 2 m 5$ & This paper \\
\hline
\end{tabular}

tend the Sather method also to observations at phase angles smaller than 8.5 .

We try in a qualitative way to take into account the amplitude phase relation, giving a smaller weight to observations at very large or very small phase angles. These am- plitudes are marked with colons in Tables III, IV, V, and VI. We know, in fact, that observations at different phase angles, owing to the shadowing effect on a macroscopically rough surface, can present quite different amplitudes. However in the case 
TABLE IV

Aspect Angles and Calculated Amplitudes for 9 Metis

\begin{tabular}{lcccc}
\hline \multicolumn{1}{c}{ Date } & $\begin{array}{c}\boldsymbol{\xi} \\
(\mathrm{deg})\end{array}$ & $\begin{array}{c}\boldsymbol{A}_{\text {cal }} \\
(\mathrm{mag})\end{array}$ & $\begin{array}{c}\boldsymbol{A}_{\text {obs }}-\boldsymbol{A}_{\text {cal }} \\
(\mathrm{mag})\end{array}$ \\
\hline 1949 Nov 2 & +56 & 0.11 & 0.00 \\
1954 Jan 3 & -87 & 0.28 & -0.02 \\
1954 Jan 5 & -87 & 0.28 & -0.02 \\
1954 Jan 8 & -87 & - & - \\
1954 Jan 16 & -88 & 0.28 & -0.03 \\
1958 Feb 15 & -55 & 0.10 & -0.01 \\
1962 Mar 26 & -48 & 0.07 & -0.01 \\
1962 Mar 30 & -48 & 0.07 & -0.01 \\
1964 Nov 19 & +87 & 0.28 & $+0.03:$ \\
1974 Jun 24 & +79 & 0.25 & +0.03 \\
\hline
\end{tabular}

of 9 Metis all the observations were performed at phase angles varying from 2 to $9^{\circ}$, this small range of phase implying a small change in the amplitudes; therefore they can be considered homogeneous, excluding the observation of 1964 that, as we shall point out in the next section on pole determination, was not used to fix the maximum possible amplitude. For 44 Nysa we used similar considerations looking for the best fit for the amplitudes from 5 to $11^{\circ}$ of phase, and giving less weight to the amplitudes derived at other phase angles, which therefore present larger residuals. No determination of the sense of rotation was attempted because of the time intervals being too large.

\section{THE OBSERVATIONS}

\section{General Remarks}

Asteroids 9 Metis and 44 Nysa were observed photoelectrically in 1974 over a time interval somewhat longer than their known periods. Asteroid 22 Kalliope could be observed in 1965 and 1974 over a time interval almost as long as its period.

The observations were made with the Walraven photometer attached to the $90-\mathrm{cm}$ light collector of the Leiden Southern Station, in colors $V$ and $B$. The comparison stars used in 1974 were calibrated in 1974 and 1977 by C. J. van Houten and 1978 by $A$. van Genderen. The comparison star for Kalliope in 1965 was also calibrated by J. W. Pel in 1970. The transformation from the Walraven system to the $U B V$ system was done in the same way as described in Zappalà et al. (1979).

The observational results are summarized in Table I. The columns are selfexplanatory: the first four columns give the number of the asteroid followed by the mean time of observation in UT, the position for 1950 . The magnitude $V_{0}$, the brightness of the brighter maximum, is followed by $\bar{V}$, the mean brightness over a full period, $B-V$, the amplitude $M_{1}-m_{1}$, the period from Taylor's list, the comparison star and its $V$ magnitude. Table II gives the Julian Date, corrected for lighttime of the extrema for the three asteroids.

TABLE V

Aspect Data and Magnitudes for 44 Nysa

\begin{tabular}{|c|c|c|c|c|c|c|c|c|c|c|c|}
\hline $\begin{array}{c}\text { Date } \\
\left(\mathrm{O}^{\mathrm{h}} \mathrm{UT}\right)\end{array}$ & $\begin{array}{c}\lambda(\text { deg }) \\
(1950)\end{array}$ & $\begin{array}{c}\beta(\mathrm{deg}) \\
(1950)\end{array}$ & $\frac{\Delta}{(A U)}$ & $\stackrel{r}{(A U)}$ & $\begin{array}{c}\alpha \\
\text { (deg) }\end{array}$ & $\begin{array}{c}V_{0}(1, \alpha) \\
(\operatorname{mag})\end{array}$ & $\begin{array}{l}\bar{V}(1, \alpha) \\
\text { (mag) }\end{array}$ & $\begin{array}{l}\text { Amp. } \\
\text { (mag) }\end{array}$ & $\begin{array}{c}B-V \\
(\mathrm{mag})\end{array}$ & Period & Reference \\
\hline 1949 Nov & 18.45 & -6.03 & 1.405 & 2.339 & 10.5 & 7.35 & 7.54 & 0.46 & - & $6^{\mathrm{h}} 25^{\mathrm{m}}$ & f \\
\hline 1949 Nov & 18.25 & -6.01 & 1.409 & 2.337 & 10.9 & 7.35 & 7.55 & 0.48 & - & $6^{\mathrm{h}} 25^{\mathrm{m}}$ & f \\
\hline 1954 Jan & 51.45 & -4.81 & 1.387 & 2.122 & 21.9 & 7.51 & 7.70 & $0.40:$ & - & $6^{\mathrm{h}} 25 \mathrm{~m} 2$ & b \\
\hline 1954 Jan & 51.49 & -4.77 & 1.396 & 2.121 & 22.2 & 7.51 & - & - & 0.70 & $6^{\mathrm{h}} 25^{\mathrm{m}} 2$ & b \\
\hline 1954 Jan 11 & 51.72 & -4.57 & 1.430 & 2.117 & 23.3 & 7.51 & 7.70 & $0.41:$ & - & $6^{\mathrm{h}} 25^{\mathrm{m}} 2$ & b \\
\hline 1958 Jan 13 & 98.72 & -3.10 & 1.092 & 2.060 & 6.5 & 7.13 & 7.25 & 0.22 & 0.70 & $6^{\mathrm{h}} 28^{\mathrm{m}}$ & $\mathrm{c}$ \\
\hline 1962 Mar 2 & 144.37 & +2.40 & 1.154 & 2.124 & 7.2 & - & - & 0.29 & - & $6^{\mathrm{h}} 25^{\mathrm{m}} 1$ & d \\
\hline 1964 Oct 8 & 12.24 & -5.54 & 1.436 & 2.432 & 2.5 & - & - & $0.38:$ & - & $6^{\mathrm{h}} 25^{\mathrm{m}} \cdot 3$ & $\mathrm{e}$ \\
\hline 1964 Oct 29 & 7.43 & -0.56 & 1.476 & 2.396 & 11.4 & - & - & 0.50 & - & $6^{\mathrm{h}} 25^{\mathrm{m}} \cdot 3$ & $\mathrm{e}$ \\
\hline 1974 May 17 & 246.98 & +5.59 & 1.621 & 2.616 & 4.9 & 7.13 & 7.27 & 0.28 & 0.71 & $6^{\mathrm{n}} 29^{\mathrm{m}}$ & This paper \\
\hline
\end{tabular}


TABLE VI

Aspect Angles and Calculated Amplitudes for 44 NYSA

\begin{tabular}{lccc}
\hline \multicolumn{1}{c}{ Date } & $\begin{array}{c}\xi \\
(\mathrm{deg})\end{array}$ & $\begin{array}{c}\boldsymbol{A}_{\text {cal }} \\
(\mathrm{mag})\end{array}$ & $\begin{array}{c}\boldsymbol{A}_{\text {obs }}-\boldsymbol{A}_{\text {cal }} \\
(\mathrm{mag})\end{array}$ \\
\hline 1949 Nov 6 & -89 & 0.50 & -0.04 \\
1949 Nov 7 & -89 & 0.50 & -0.02 \\
1954 Jan 6 & -69 & 0.35 & +0.05 \\
1954 Jan 7 & -69 & 0.35 & - \\
1954 Jan 11 & -69 & 0.35 & $+0.06:$ \\
1958 Jan 13 & -53 & 0.20 & +0.02 \\
1962 Mar 2 & -61 & 0.27 & +0.02 \\
1964 Oct 8 & +87 & 0.49 & -0.11 \\
1964 Oct 29 & +87 & 0.49 & -0.01 \\
1974 May 17 & +63 & 0.29 & -0.01 \\
\hline
\end{tabular}

Figures 1-4 show the lightcurves of the three objects. Each point is a single observation. The ordinates $\Delta V^{\prime}$ are the magnitude differences: asteroid minus comparison star in the $V$ band of the Walraven color system. The abscissas give the time of observation uncorrected for lighttime.

For Metis and Nysa we attempted to derive a new value of the period by checking the time interval of the same branch of the lightcurve. The accuracy of the determination is poor.

\section{Metis}

Metis is a very interesting object. The shapes of the lightcurves observed between 1949 and 1974 are very different. The plot of the mean lightcurves from the oppositions 1949, 1954, 1958, 1964, and 1974 in Fig. 5 illustrates the changes of the shape with as- pect angle. In 1949, 1954, and 1974 we see one broad and one sharp minimum; and it seems that in 1964 this difference in the minima is also present. But in 1958 and also in 1962 only one maximum and one minimum are visible. In 1974 the two maxima and the two minima have almost the same brightness. Therefore we are not certain which of the maxima is the primary one. We favor the maximum preceding the broader minimum as the primary maximum, in agreement with 1949,1954 , and 1964 . These differences in amplitude and shape of the lightcurve would then be attributed to a combination of the change in aspect and the change of the phase angle.

The period determined from our lightcurve is $5^{\mathrm{h}} 2^{\mathrm{m}} 5$ which is smaller than the ones derived earlier.

Before going over to the next asteroids, we want to call attention to the fact that the position of Metis in the table of the publication of Yang et al. (1965) is valid for 1964 Oct. 19 and for Nov. 19, as given in their Fig. 2. Accordingly we do not know the correct month of their observation.

\section{Kalliope}

The 1965 lightcurve of Kalliope gives the largest amplitude so far observed and the 1974 lightcurve gives the smallest one. The difference between maximum I and maximum II is in both years about $0.01 \mathrm{mag}$. The amplitude in the $B$ band is the same as in the $V$ band. The period can only be estimated to about $4^{\mathrm{h}} 8^{\mathrm{m}}$ in both years, which

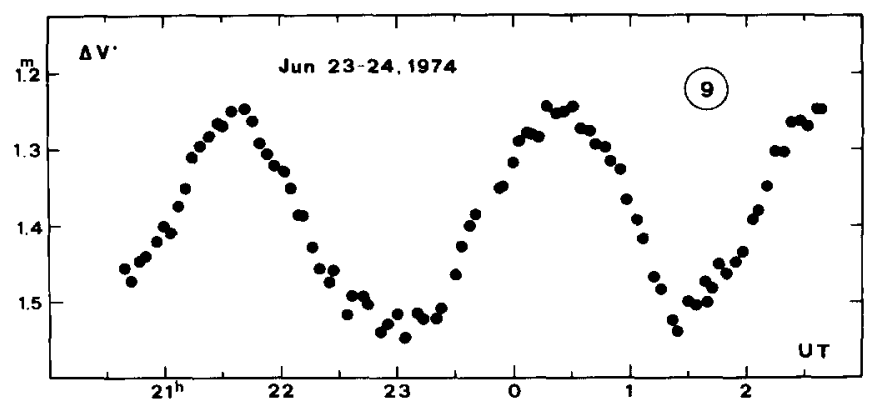

FIG. 1. Lightcurve of 9 Metis on June 23-24, 1974. 


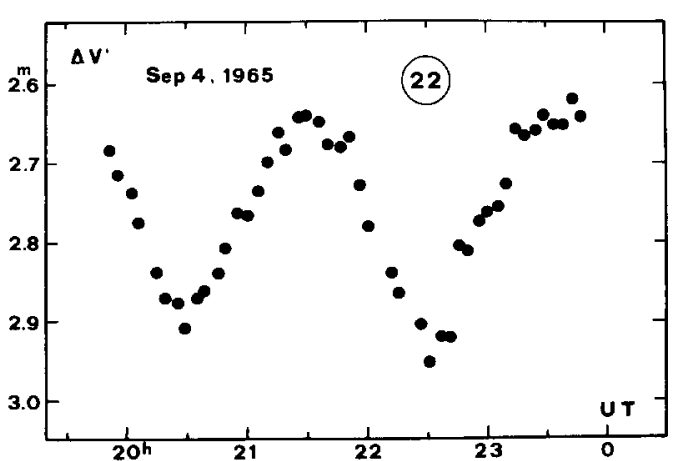

FIG. 2. Lightcurve of 22 Kalliope on September 4, 1965.

agrees fairly well with the period determined by Scaltriti et al. (1978).

\section{Nysa}

Figure 4 shows the lightcurve of 44 Nysa on 1974 May 16-17. Using observations which overlapped by only about $40 \mathrm{~min}$, we obtained $6^{\mathrm{h}} 29^{\mathrm{m}}$ as a mean value for the period, which is in agreement with the period of $6^{\mathrm{h}} 28^{\mathrm{m}} \pm 2^{\mathrm{m}}$ determined in 1958 . If we compare the lightcurves of the different years, we see that the sequence of the extrema is variable. For 1964 it is difficult to decide which of the maxima is the brighter one. During several years the minima were almost the same.

Note that the value of $B-V=0.67$ given for 44 Nysa in Taylor's list (1971) and in subsequent publications that refer to this list must be erroneous. Taylor quotes only two $B-V$ determinations: Groeneveld and

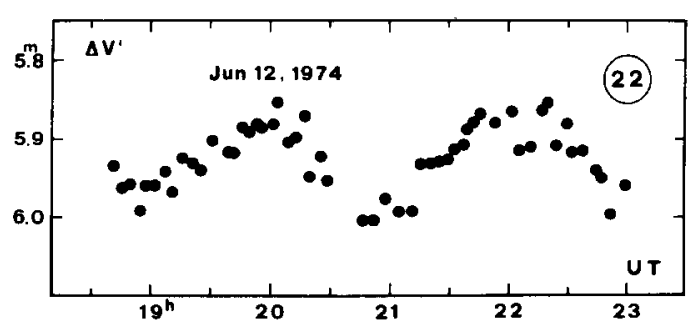

FIG. 3. Lightcurve of 22 Kalliope on June 12, 1974.

Kuiper (1954) and Gehrels and Owings (1962), both of which give $B-V=0.70$.

\section{POLE DETERMINATIONS}

\section{Metis}

Table III reports information on all photoelectric observations of this asteroid. The columns give: the date, the ecliptic coordinates at 1950, the heliocentric and geocentric distances, the phase angle, the $V_{0}(1, \alpha)$ of the primary maximum, $\bar{V}(1, \alpha)$ the mean magnitude, the maximum amplitude, and the reference. The Ephemerides were kindly sent to us by Herget (1978).

Gehrels and Owings (1962) found a possible pole of $\lambda_{0}=186^{\circ}$ and $\beta_{0}=15^{\circ}$ using an empirical dependence of the amplitudes and magnitudes with aspect angles. With this pole the greatest possible amplitude should be $0.23 \mathrm{mag}$. However, at least this last conclusion is not confirmed by the observations given in Table III.

We start our fitting process near this value of the pole, taking $b / c$ ratios ( $c$ being the rotational axis) varying from 1.0 to 2.0

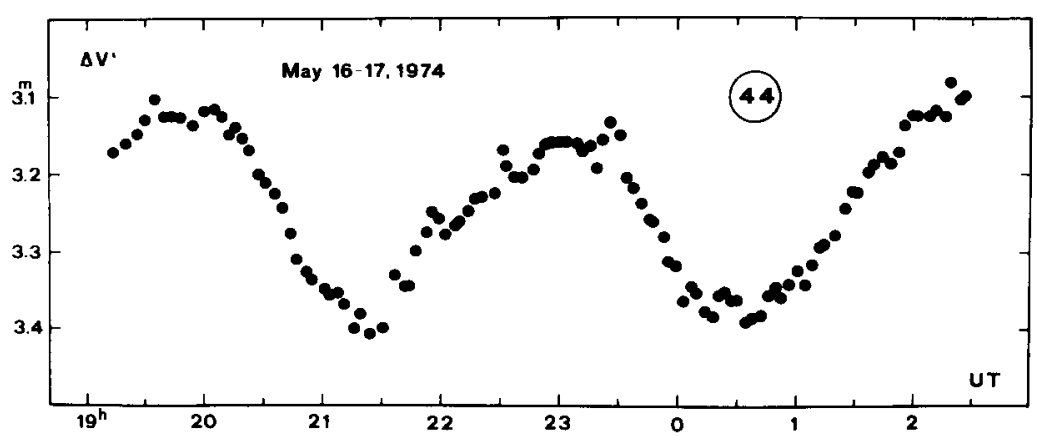

FIG. 4. Lightcurve of 44 Nysa on May 16-17, 1974. 


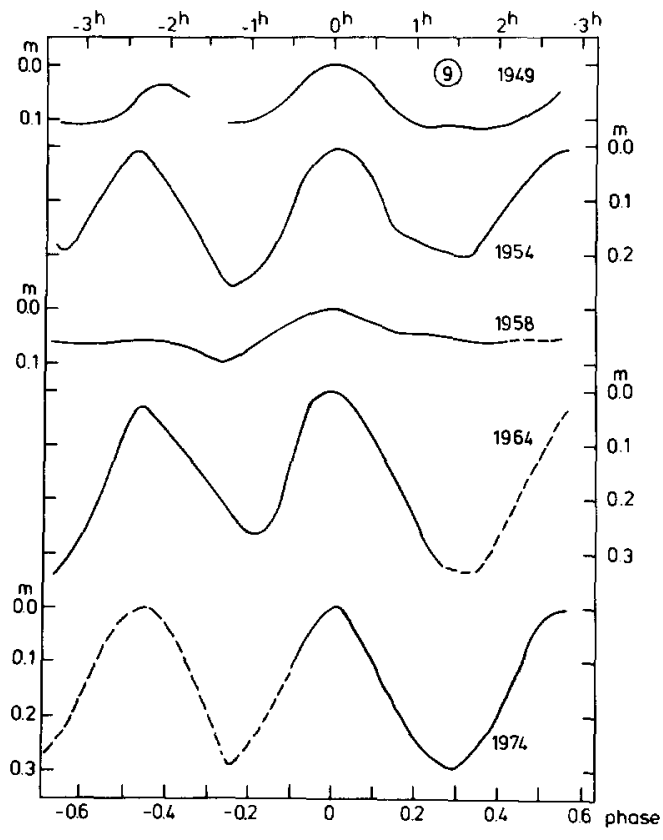

FIG. 5. Mean lightcurve of 9 Metis in 1949, 1954, 1958, 1964, and 1974 apparition. The smooth curve gives a representation through the observations, the dashed curve represents observations transformed, without corrections for changes in distance and phase angle, to one period earlier or later. The ordinate gives the magnitude, the abscissa above, the hours, below, the phase of the period. The eclipse coordinates and the phase angles are:

\begin{tabular}{rrlr} 
& $\lambda$ & \multicolumn{1}{c}{$\beta$} & $\alpha$ \\
\hline 1949 & $41^{\circ}$ & $-5^{\circ}$ & $2^{\circ}$ \\
1954 & $97^{\circ}$ & $+6^{\circ}$ & $5^{\circ}$ \\
1958 & $153^{\circ}$ & $+9.5^{\circ}$ & $5^{\circ}$ \\
1964 & $94^{\circ}$ & $+1^{\circ}$ & $17^{\circ}$ \\
1974 & $294^{\circ}$ & $-5^{\circ}$ & $8^{\circ}$
\end{tabular}

and we obtain possible poles between 180 and $200^{\circ}$ in $\lambda$ and between 30 and $60^{\circ}$ in $\beta$. An analysis of the amplitudes finally gives a value of $\lambda_{0}=191^{\circ} \pm 5^{\circ}$ and $\beta_{0}=56^{\circ} \pm 6^{\circ}$, with $b / c=1.70$. The maximum possible amplitude was taken to be $0.28 \mathrm{mag}$ as deduced from a plot of the amplitudes versus the longitudes, from which we derive a value of $a / b=1.30$. The value of $0.31 \mathrm{mag}$ obtained by Yang et al. (1965) was probably influenced by the phase effect on the amplitudes $(\alpha=16.8)$. Table IV reports the aspect angles, the calculated amplitudes and the differences between the observed and the calculated amplitudes for all the available observations. Figure 6 shows the uncorrected phase curve (above) and the same curve for $90^{\circ}$ of aspect (below). The straight line was drawn with a slope equal to the mean phase coefficient of $0.028 \mathrm{mag} / \mathrm{deg}$ for the $S$-type as found by Bowell (1978). The resulting $V_{0}(1,0,90)$ is $6.66 \mathrm{mag}$.

The dimensions of our object can be found from the following expression:

$$
2 \log r=5.642-0.4 V(1,0)-\log p_{\mathrm{v}}
$$

( $r=$ radius in kilometers) in which $r^{2}=a c$. Inserting the value for the geometrical albedo $p_{\mathrm{v}}=0.139$ as adopted by Morrison (1976), we find that the dimensions are roughly $245 \times 190 \times 110 \mathrm{~km}^{3}$.

\section{Kalliope}

The aspect data and preliminary results on the amplitude for 1965 and 1974 of Kalliope have previously been presented by Scaltriti et al. (1978). The definitive magnitude of the 1965 comparison star is $0 \mathrm{~m}^{\mathrm{m}} 01$ brighter than given in Scaltriti's Table I, and consequently $V_{0}(1, \alpha)$ becomes $7^{\mathrm{m}} 19$. Now the definitive reduction allows us to

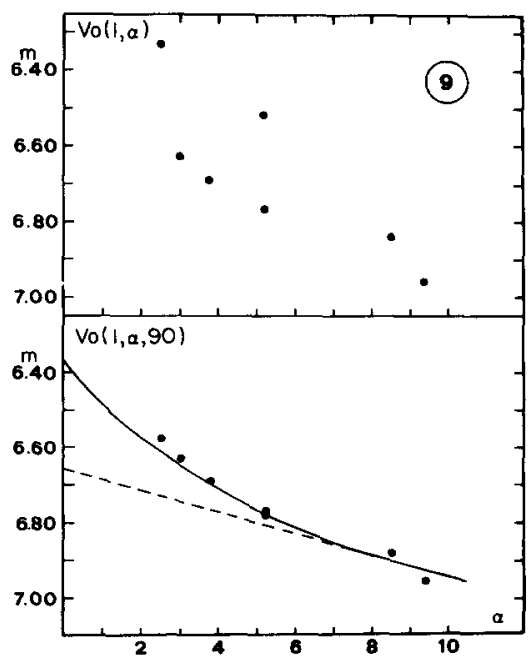

Fig. 6. Phase curves of 9 Metis. The uncorrected relation (above) and the relation reduced to $90^{\circ}$ of aspect (below) by pole coordinates $\lambda_{0}=191^{\circ}$ and $\beta_{0}=56^{\circ}$. 


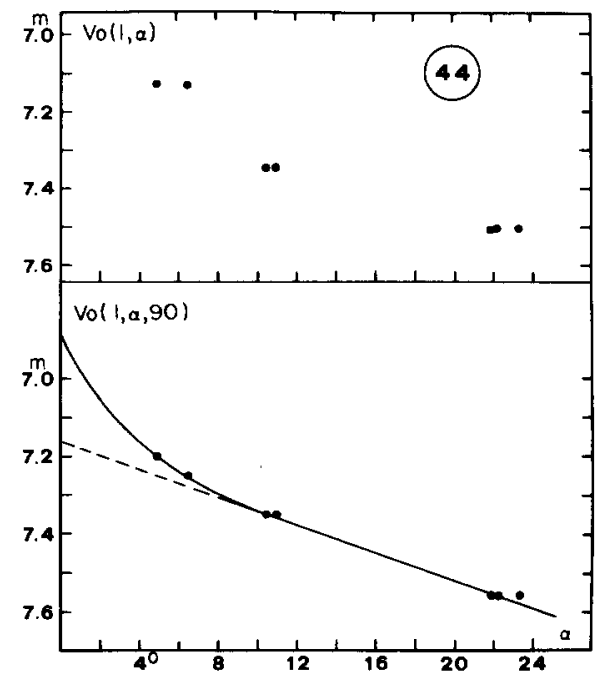

FIg. 7. Phase curves of 44 Nysa. The uncorrected relation (above) and the relation reduced to $90^{\circ}$ of aspect (below) by pole coordinates $\lambda_{0}=100^{\circ}$ and $\beta_{0}=50^{\circ}$.

check the value of the pole using the magnitude, reduced to unit distances and to $90^{\circ}$ of aspect. We have for $1965, V_{0}(1$, 13.0) $=7^{\mathrm{m}} 19$ which becomes $V_{0}(1,13.0$, 90) $=7.20$ and, for $1974, V_{0}(1,7.7)=6^{\mathrm{m}} .93$ which becomes $V_{0}(1,7.7,90)=7.06$ in very good agreement with the phase relation $V_{0}(1,0,90)=6.80+0.031 \alpha$. The 1965 value deviates by 0.00 and the 1974 value only 0.02 from this relation.

\section{Nysa}

Table $\mathrm{V}$ gives information about Nysa corresponding to Table III. For 44 Nysa, Gehrels and Owings (1962) obtained a pole direction of $\lambda_{0}=105^{\circ}$ and $\beta_{0}=30^{\circ}$. By analogous calculations as for 9 Metis, we obtain $\lambda_{0}=100^{\circ} \pm 10^{\circ}$ and $\beta_{0}=50^{\circ} \pm 10^{\circ}$, confirming the previous result of Gehrels and Owings. The $b / c$ ratio is 1.30 . We adopted $a / b=1.58$ considering a maximum possible amplitude of $0.50 \mathrm{mag}$ suggested by an amplitude-longitude plot. We note that the amplitudes corresponding to very large or very small phase angles have larger residuals, implying a strong amplitude-phase relation. The results are given in Table VI, which is similar in structure to Table IV. Figure 7 shows the phase curves.

The resulting $V_{0}(1,0,90)$ is $7.16 \mathrm{mag}$, which together with the geometrical albedo $p_{\mathrm{v}}=0.377$ as given by Morrison (1976) leads to dimensions of $115 \times 70 \times 55 \mathrm{~km}^{3}$.

The phase coefficient of $0.018 \mathrm{mag} / \mathrm{deg}$ derived here confirms the already suggested dependence of this parameter with the geometrical albedo (Bowell, 1978). Figure 8 shows the plot $\beta_{v}$ versus $p_{v}$ for all published values as collected by Tedesco (1978). The open circles should be lower than drawn because they were derived from mean $V$ phase curves for asteroids showing a welldefined amplitude-phase relation. The final results for the three asteroids are summarized in Table VII.

\section{DISCUSSION}

Methods for determining poles of asteroids in use at present are far from satisfactory. Several methods have been used in

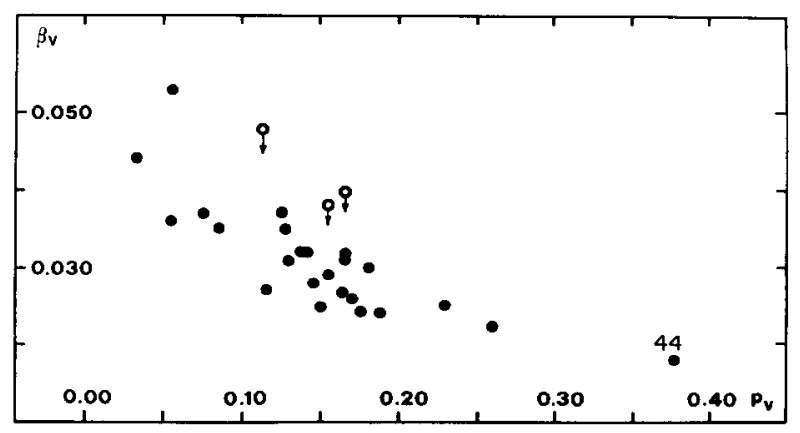

FIG. 8. Phase coefficient versus geometrical albedo. The open circles refer to asteroids showing a well-defined amplitude-phase relation and for which a mean $\mathrm{V}$ phase coefficient was given. 
TABLE VII

Final Results

\begin{tabular}{lccc}
\hline & & Asteroid & 44 \\
\cline { 2 - 4 } & 9 & 22 & 7.16 \\
\hline$V_{0}(1,0,90)(\mathrm{mag})$ & 6.66 & 6.80 & 7.35 \\
$\bar{V}(1,0,90)(\mathrm{mag})$ & 6.80 & 6.92 & 0.71 \\
B V (mag) & 0.85 & 0.72 & 0.018 \\
Phase coefficient (mag/deg) & 0.028 & 0.031 & $100^{\circ} \pm 10^{\circ}$ \\
Direction of pole & $191^{\circ} \pm 5^{\circ}$ & $215^{\circ} \pm 10^{\circ}$ & $50^{\circ} \pm 10^{\circ}$ \\
$\quad \lambda_{0}$ & $56^{\circ} \pm 6^{\circ}$ & $45^{\circ} \pm 15^{\circ}$ & $115 \times 70 \times 55$ \\
$\beta_{0}$ & $245 \times 190 \times 110$ & $215 \times 160 \times 130$ & $6^{\mathrm{h}} 29^{\mathrm{m}} \pm 2^{\mathrm{m}}$ \\
Dimensions $(\mathrm{km})$ & $5^{\mathrm{h}} 2^{\mathrm{m}} 5 \pm 2^{\mathrm{m}}$ & $4^{\mathrm{h}} 8^{\mathrm{m}} \pm 3^{\mathrm{m}}$ & \\
Period & \multicolumn{2}{c}{}
\end{tabular}

the last years, but for all of them some restrictive assumptions have to be made.

Regarding the method used in this paper, the model of a three-axial ellipsoid cannot be universally applicable. Existence of irregular shapes and macroscopic features on the surface of the asteroids reduce the number of objects for which this method can be used. Comparison with results obtained with other methods like photometric astrometry could be very interesting.

Even if pole determinations based on the relation between amplitude c.q. magnitude and aspect cannot give values of high precision, this kind of work can be very useful for statistical researches and, at least, can provide a starting point for more precise analysis.

We conclude that international campaigns to follow selected asteroids during some continuous oppositions should be encouraged.

\section{ACKNOWLEDGMENTS}

The authors want to express their thanks to Mr. W. van Vliet for observing asteroids 9,22 , and 44 during three nights in 1974. We are also very grateful to Dr. C. J. van Houten for many stimulating discussions. Finally, we would like to thank Dr. C. Vesely for the valuable suggestions on this paper given during the Asteroid Meeting held in Tucson in March 1979.

\section{REFERENCES}

Bowell, E. (1978). Private communication, Lowell Observatory, Flagstaff, Ariz.
Chang, Y. C., And Chang, C. S. (1962). Photometric investigation of seven variable asteroids. Acta Astron. Sinica 10, 101-111 (d).

Gehrels, T., And Owings, D. (1962). Photometric studies of asteroids. IX. Additional light-curves. Astrophys. J. 135, 906-924 (c).

Groeneveld, I., And Kupier, G. P. (1954). Photometric studies of asteroids, I. Astrophys. J. 120, 200-220 (a).

Groeneveld, I., And Kuiper, G. P. (1954). Photometric studies of asteroids, II. Astrophys. J. 120, 529-546 (b).

Herget, P. (1978). Private communication. M.P.C., Cincinnati, Ohio.

Morrison, D. (1977). Asteroid sizes and albedos. Icarus 31, 185-220.

SATHER, R. E. (1976). Minor planets and related objects. XIX. Shape and pole orientation of (39) Laetitia. Astron. J. 81, 67-73.

SCaltriti, F., Zappalà, V., And Stanzel, R. (1978). Lightcurves, phase function and pole of the asteroid 22 Kalliope. Icarus 34, 93-98.

Shatzel, A. V. (1954). Photometric studies of asteroids. III. The lightcurve of 44 Nysa. Astrophys. J. 120, 547-550. (f).

TAYloR, R. C. (1971). Physical studies of minor planets, NASA SP267, p. 117.

Tedesco, E. F. (1978). Private communication, Lunar and Planetary Laboratory, University of Arizona, Tucson.

Yang, XIU-YI, Zhang, You-Yi, and LI, XiaOQuING (1965). Photometric observations of variable asteroids, III. Acta Astron. Sinica 13, 66-74 (e).

ZapPalà, V., Houten-Groeneveld, I. VAN, AND Houten, C. J. VAN (1979). Rotation period and phase curve of the asteroids 349 Dembowska and 354 Eleonora. Astron. Astrophys. Suppl. 35, 213-221. 